Viso: Cadernos de estética aplicada

Revista eletrônica de estética

ISSN 1981-4062

$\mathrm{N}^{\circ} 29$, jul-dez/2021

http://www.revistaviso.com.br/

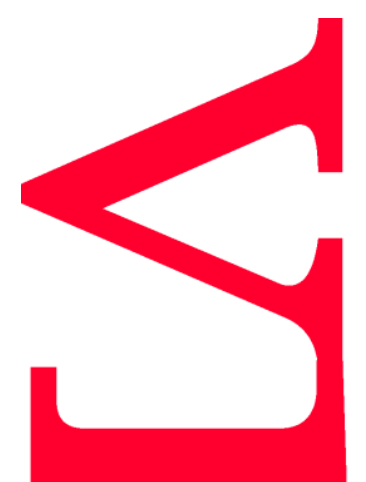

\title{
O corpo a corpo da crítica: do prazer estético como efeito narrativo Patrick Pessoa
}




\section{RESUMO}

O corpo a corpo da crítica: do prazer estético como efeito narrativo

Apresentado oralmente no X Encontro do GT de Estética da ANPOF, o presente texto foi construído como um diálogo filosófico com as "Teses sobre a estetosfera", apresentadas por Rodrigo Duarte no mesmo evento e também publicadas no número 29 da Revista Viso.

Palavras-chave

crítica; teatro; nachträglich; Machado de Assis; Freud; Adorno

\section{ABSTRACT}

The Body of Criticism: On Aesthetic Pleasure as a Narrative Effect

Presented orally at the X Meeting of the GT on Aesthetics of ANPOF, the present text was constructed as a philosophical dialogue with the "Theses on the stethosphere", presented by Rodrigo Duarte at the same event and also published in number 29 of Revista Viso.

Keywords

criticism; theater; nachträglich; Machado de Assis; Freud; Adorno 
PESSOA, Patrick. "O corpo a corpo da crítica: do prazer estético como efeito narrativo". Viso: Cadernos de estética aplicada, v. 15, n²9 (jul-dez/2021), p. 204212.

DOI: $\underline{10.22409 / 1981-4062 / v 29 i / 445}$

Aprovado: 21.01.2022. Publicado: 30.01.2022.

(C) 2021 Patrick Pessoa. Esse documento é distribuído nos termos da licença Creative Commons Atribuição-NãoComercial 4.0 Internacional (CC-BY-NC), que permite, exceto para fins comerciais, copiar e redistribuir o material em qualquer formato ou meio, bem como remixá-lo, transformá-lo ou criar a partir dele, desde que seja dado o devido crédito e indicada a licença sob a qual ele foi originalmente publicado.

Licença: http://creativecommons.org/licenses/by-nc/4.0/deed.pt_BR

Accepted: 21.01.2022. Published: 30.01.2022.

(C) 2021 Patrick Pessoa. This document is distributed under the terms of a Creative Commons Attribution-NonCommercial 4.0 International license (CC-BY-NC) which allows, except for commercial purposes, to copy and redistribute the material in any medium or format and to remix, transform, and build upon the material, provided the original work is properly cited and states its license.

License: http://creativecommons.org/licenses/by-nc/4.0/ 
- Rodrigo, meu caro, ainda me lembro de uma intervenção provocativa que você fez depois de uma fala minha na ANPOF de 2006, em Salvador, quando comecei a me aproximar do GT de Estética. Era a época em que eu dava aulas de filosofia para a Maria Celina, mãe da Virginia Figueiredo, num grupo de senhoras fantásticas que se reuniam quinzenalmente na casa da minha avó, e foi também nessa ocasião que conheci a Virginia pessoalmente. Lá se vão 15 anos. Então é uma alegria estar aqui vendo que, apesar dessa pandemia grotesca, o GT de Estética sobrevive. Parabenizo ao Pedro Hussak pela ótima organização deste evento. Outra alegria é, pela primeira vez nesse tempo todo, estar escalado para fazer uma breve intervenção comentando um texto teu na companhia da Debora [Pazetto], que escreveu um dos ensaios de que mais gosto na história da Viso, chamado "Destino e liberdade: um ensaio sobre a teleologia latente na filosofia da arte de Arthur Danto".

Rodrigo, como você elaborou o teu texto na forma de teses, "Teses sobre a estetosfera", tomei a liberdade de elaborar o meu comentário na forma de pequenos fragmentos. Não sei se eles contêm alguma tese, mas resolvi te imitar, de modo que eles também estão numerados em algarismos romanos. Sei que a recomendação era que a gente apresentasse oralmente as nossas intervenções neste evento, sem ler, então peço a vocês que imaginem que estou improvisando as palavras que se seguem. Vou me esforçar também para fingir que não estou, quer dizer, que não tôlendo.

"Um conjunto de estímulos sensoriais capazes de atingir simultaneamente pelo menos 3 dos 5 sentidos da percepção humana, ocasionando um tipo de sentimento que a tradição ocidental batizou de prazer estético". Essa é a definição de estetosfera segundo o Rodrigo Duarte: "um conjunto de estímulos sensoriais" determinado pelo tipo de efeito que produz, a saber, "prazer estético". 
Bom, se a definição depende do efeito, ela vai ser sempre $a$ posteriori- nachträglich, no dizer de Freud; ou póstuma, no dizer de Brás Cubas. (Se o meu doutorado sanduíche na Alemanha serviu para alguma coisa, foi para entender na pele como funciona o racismo nas bandas de lá, mas também para ler um livro chamado Die nachträglichen Memoiren des Bras Cubas, o que fez toda a diferença para a minha interpretação do Machado, da psicanálise e da vida.) É que dá uma certa calma saber, sobretudo quando a gente vê muita peça de teatro, que as coisas acontecem pra valer é no "nach", no depois, no tipo de associações que a gente traz depois, no trabalho da memória. ${ }^{1}$ Se essas associações são livres ou são determinadas, se fazem justiça à peça original ou não, dava uma conversa mais longa, que adoraria continuar outro dia.

Só pra não falar de uma coisa dizendo que não dá tempo de falar direito dela (afinal, pra nós, mortais, nunca dá tempo mesmo de falar direito de nada!), deixa eu só fazer uma associação livremente determinada ou determinadamente livre (como vocês preferirem). No prefácio que a Anne Carson escreveu para uma tradução que fez do Hipólito de Eurípides, ela diz assim:

Essa "grande" questão do livre arbítrio e do determinismo me faz pensar num ovo cozido. Corte-o ao meio. Você verá um desenho requintado - o círculo amarelo está perfeitamente suspenso no molde oval branco. As duas figuras estão separadas e são diferentes, e mesmo assim constroem uma forma. Elas não se contradizem ou cancelam, elas interexistem. Você pode dizer que alguma delas é mais determinante? 0 círculo como um oval distorcido? O oval como um círculo imperfeito? Em vez disso, cada uma segue a outra num sistema perfeito chamado ovo. ${ }^{2}$

II

Anne Carson me levou tão longe que vou ter que abrir outro fragmento pra conseguir voltar pro texto do Rodrigo.

O meu Fragmento II (que ainda é sobre a calma de as coisas acontecerem pra valer sempre no "depois") parece um aforismo. 
Diz assim: "Se não acontece nada agora, paciência que o jogo ainda não está perdido". (Ouvindo esse aforismo, um aluno gaiato retrucou: "Mas, professor, você não acha importante que pelo menos alguma coisa aconteça agora?!") Enfim...

O agora, pra mim, permanece sempre só uma noção meio abstrata, como se a ele faltasse presença, consistência, realidade, como se eu vivesse imerso num tipo de bruma fantasmagórica. Na Tempestade, o Shakespeare diz que "nós somos feitos da mesma matéria de que são feitos os sonhos" e arremata dizendo que "a nossa pequena vida está cercada de sono". ${ }^{3}$ É mais ou menos isso que estou tentando dizer, que a gente é feita da mesma matéria dos sonhos.

Exceto, senhor William, e o senhor sabe disso como poucos, quando a gente narra um sonho. Na narrativa, na contação de um causo singular, no corpo a corpo com uma experiência estética específica (estetosférica ou não) - corpo a corpo é outro possível nome para crítica! - algo pode acontecer, se realizar, se encarnar, se incorporar. Por instantes efêmeros, talvez, a nossa pequena vida deixa de estar embebida em sono (ou em sonho). Abrimos os olhos, despertamos.

Não é esse sentimento, que bate mais forte quando a gente conta alguma coisa (mesmo que seja só para nós mesmos), que a tradição ocidental chama de "prazer estético"? Eu sei que não sou ocidental e não devia ficar aqui falando em nome da tradição dos outros, mas tem prazer estético independentemente do trabalho de a gente narrativizar o que nos acontece, acomete, atravessa, traga e traça?

III

Por isso, Rodrigo, preciso confessar que, vindo da minha antiga militância em torno do conceito de estética aplicada, estranhei a forma que você escolheu: a forma de "teses". Curtas e densas, numeradas em algarismos romanos de I a XXII, mas sem o apoio de nenhuma análise de obra, de nenhuma narrativa, de nenhum causo contado. Você enuncia vinte e duas teses, tentando cercar 
conceitualmente por vários lados o teu conceito de "estetosfera", mas o modo como as teses elas próprias são apresentadas não me colocou nesse elemento estetosférico que me permitiria não apenas compreender de forma abstrata, mas experimentar na carne o teu conceito.

Como tinha sentido isso já depois da primeira leitura, você deve se lembrar que pedi para você me mandar "os recursos complementares à exposição oral" (como estava escrito no final do teu texto) - dois vídeos que, salvo engano, você mesmo realizou. ${ }^{4}$ Mas confesso que esses materiais não desfizeram inteiramente o meu incômodo. Afinal, eu esperava que a experiência que você fez no momento em que participou desses eventos registrados em vídeo estivesse narrada com maior minúcia no próprio texto. Sem essa narração, ou ao menos uma descrição pessoal tua, as teses ainda estavam abstratas demais para mim, como que embebidas em sono. Sou desses que acreditam que uma crítica em prosa ensaística de um espetáculo teatral ou performático é uma memória e um tipo de documentação das artes da cena muito mais poderoso do que qualquer registro filmado. $E$ acho que teu conceito de estetosfera diz respeito eminentemente às artes vivas ou artes da presença. Você estaria de acordo com essa tese sobre as tuas teses?

\section{IV}

Pra terminar, e este é meu quarto e último fragmento, vou trazer aqui para a nossa mesa um grande amigo teu, o Teddy. No "Ensaio como forma", ele diz mais ou menos o seguinte:

O ensaio se aproxima de uma autonomia estética que pode ser facilmente acusada de ter sido tomada de empréstimo à arte, embora o ensaio se diferencie da arte tanto por seu meio específico, os conceitos, quando por sua pretensão à verdade desprovida de aparência estética. É isso o que Lukács não percebeu quando, na carta a Leo Popper que serve de introdução ao livro $A$ alma e as formas, definiu o ensaio como uma forma de arte. No entanto, a máxima positivista segundo a qual os 
escritos sobre a arte não devem jamais almejar um modo de apresentação artístico, ou seja, uma autonomia da forma, não é melhor do que a concepção de Lukács. Como seria possível falar do estético de modo não estético, sem qualquer proximidade com o objeto, e não se desviar do próprio assunto ${ }^{5}$

Deixo então como provocação inicial para o nosso debate duas séries de questões.

A primeira: teses seriam mesmo a melhor forma de apresentação de uma noção tão singular quanto essa de estetosfera? Teses não seriam tendencialmente genéricas demais, a ponto de não conseguirem reter entre os dedos a singularidade absoluta dos eventos aos quais você acabou de fazer referência na tua fala e que te inspiraram a conceber a noção de estetosfera? Narrativas breves sobre encontros singulares não seriam mais adequadas do que teses?

A segunda: será que o conceito de "estetosfera", atrelado ao conceito de um "prazer estético" específico e autônomo que tal estetosfera propiciaria, não entra em contradição com a ideia de mistura dos cinco sentidos da percepção humana, que implica uma certa mescla do belo, do bom e do agradável? Os diversos âmbitos da experiência humana (o ético, o erótico, o político, o epistemológico) que estão implicados no teu conceito de estetosfera não seriam inseparáveis? Assim, não te parece que falar de estetosfera é partir de uma separação entre o âmbito estético e os demais para, num segundo momento, tentar superar essa separação? Se o movimento é no sentido de superar essa separação, não faria mais sentido tentar recuar para antes dessa separação e pensar em "teses sobre a etosfera" ou mesmo em "teses sobre a aletosfera", como tentou o Lacan?

Era isso. Obrigado. 


\section{Referências bibliográficas}

ADORNO, Theodor. Notas de literatura. São Paulo: Duas Cidades; Ed. 34, 2003.

ASSIS, Joaquim Maria Machado de. Die nachträglichen Memoiren des Bras Cubas. Zurique: Manesse Verlag, 2003.

CARSON, Anne. "Prefácio a Hipólito". Tradução de Rafael Zacca. In: EURÍPEDES; CARSON, Anne. Grief Lessons. Nova York: New York Review Books, 2006.

PESSOA, Patrick. Dramaturgias da crítica. Rio de Janeiro: Cobogó, 2021.

SHAKESPEARE, W. A tempestade. Tradução de Beatriz ViégasFaria. Porto Alegre: LP\&M, 2002.

Patrick Pessoa é professor do Departamento de Filosofia da UFF.

${ }^{1}$ Cf. PESSOA, 2021, p. 15-20.

${ }^{2}$ CARSON, 2006, p. 168.

${ }^{3}$ SHAKESPEARE, 2002, p. 93.

${ }^{4}$ Tratava-se de vídeos de duas performances públicas, a céu aberto e de autoria coletiva, registradas pelo próprio Rodrigo Duarte: o Encontro Porahei Mbarete-Casa da Tia Ciata, diante do Museu do Amanhã, no Rio de Janeiro, ocorrido em 30/11/2019; e uma apresentação intitulada "Debaixo do viaduto de Santa Tereza", em Belo Horizonte.

${ }^{5}$ ADORNO, 2003, p. 18. 